\title{
Pricing music using personal data: mutually advantageous first-degree price discrimination
}

\author{
Thierry Rayna $\cdot$ John Darlington $\cdot$ Ludmila Striukova
}

Received: 17 September 2013 / Accepted: 5 August 2014 / Published online: 29 August 2014

(C) Institute of Information Management, University of St. Gallen 2014

\begin{abstract}
In addition to customized products and services, personal data also enables personalized pricing. However, consumers are often unwilling to accept being price discriminated for fear that they would end up paying more for the same product or service. This article demonstrates that by rewarding consumers for disclosing personal information it is possible to achieve a situation where first-degree price discrimination is mutually advantageous and both buyers and sellers gain by adopting such a pricing model. The conditions required for this to happen are investigated and the impact on social welfare is discussed. Finally, the article considers the robustness of this model when consumers adopt an opportunistic behavior which consists in manipulating personal data in order to masquerade as a consumer with a lower willingness to pay.
\end{abstract}

Keywords First-degree price discrimination · Digital economy $\cdot$ Pricing models $\cdot$ Personal data $\cdot$ Privacy

JEL Classification D42 $\cdot$ D82 $\cdot$ L11 $\cdot$ L82 $\cdot$ L86

Responsible editor: Sarah Spiekermann

T. Rayna $(\bowtie)$

Novancia Business School Paris,

3 rue Armand Moisant, 75015 Paris, France

e-mail: trayna@novancia.fr

J. Darlington

Imperial College London,

180 Queen's Gate, London SW7 2AZ, UK

e-mail: j.darlington@imperial.ac.uk

L. Striukova

University College London,

Gower Street, London WC1E 6BT, UK

e-mail: 1.striukova@ucl.ac.uk

\section{Introduction}

Personal data and their aggregation as 'big data' have increasingly become a central focus of the research devoted to electronic commerce. In particular, the personalization of products and services is generally considered as one of the key outcomes of the usage of big data. Beyond the creation of tailored products and services, another important aspect of big data is that it also enables price personalization. As mentioned in Spann et al. (2010), electronic media have radically changed price-making decisions. The massive amount of personal data that can be collected via electronic networks provides means to accurately assess the consumers' willingness to pay, hereby enabling first-degree price discrimination. ${ }^{1}$

Although other forms of price discrimination (e.g. versioning, freemium) have been commonly used since the early days of the internet, examples of first-degree price discrimination online are still exceedingly rare. The main reason for that is not, however, a technical one. Indeed, in 2000, Amazon delivered a proof of the feasibility of this form of price discrimination when it started to charge its consumers different prices for the same product, based on an estimation of each consumer's willingness to pay for the product. $^{2}$ At the time, the willingness to pay of consumers was calculated based on the (crude) information contained in cookies. However, this strategy rapidly backfired when some consumers realized they were paying more than others for the very same product.

\footnotetext{
${ }^{1}$ First-degree price discrimination implies that each consumer pays a different price - exactly equal to his/her willingness to pay - for the exact same product or service.

2" On the Web, Price Tags Blur - What You Pay Could Depend on Who You Are", Washington Post, Sept. 27, 2000.
} 
Indeed, while price-discrimination is profitable for businesses, it necessarily results in many consumers paying more than what they otherwise would have. Unlike other forms of price-discrimination, which are either based on self-selection (second-degree) or consumer identification based on a clear and observable group attribute ${ }^{3}$ (third-degree), first-degree price discrimination requires consumers to disclose information that would, otherwise, remain hidden. Hence, consumers with a high willingness to pay will most likely do anything they can to avoid revealing information that would lead them to be price discriminated. In contrast, consumers with a low willingness to pay ${ }^{4}$ would find it more interesting to be price-discriminated, as it would enable them to pay less or even simply to be able to buy something they could have not otherwise afforded.

Such a behavior is consistent with the literature related to privacy and information disclosure. Although generally reluctant to give up their privacy (because of concerns that the information could be used against them or create extra costs), consumers are usually ready to decrease their level of privacy as long as they are provided with sufficient incentives (Acquisti and Varian 2005; Hann et al. 2008).

One of such incentives may simply be to clearly inform consumers on how the data collected are used. Hui et al. (2007) show that the use of privacy statements by online services leads to a greater information disclosure. Financial gains (Hann et al. 2007a, b; Hui et al. 2007), especially when significant (Hann et al. 2002) can also entice consumers to give away personal data. Besides financial motives, other incentives, such as convenience (Hann et al. 2007a, b) and personal benefits (Krasnova et al. 2010), explain why people agree to disclose personal information. Hui et al. (2006) actually identify four extrinsic ("monetary saving, time saving, self-enhancement, social adjustment") and three intrinsic ("pleasure, novelty, altruism") benefits that induce consumers to decrease their privacy level.

Hence, it is possible to make consumers disclose personal information, provided that they feel properly rewarded for this disclosure. To this respect, Acquisti and Varian (2005) show that rewards, in the form of enhanced personalized services, can induce consumers to disclose personal information. Also, as discussed in Xu et al. (2003) and Chellappa and Sin (2005), trust plays an important role in consumer giving away personal data. Indeed, the more consumers trust that the data they reveal are not going to be used against

\footnotetext{
${ }^{3}$ E.g. gender, location, occupation.

${ }^{4}$ The willingness to pay for a particular product relates to both tastes and means: one might be really fond of caviar, but being on a low income, have a low willingness to pay for it. Likewise, someone on high income who does not really like caviar, may nonetheless have a high willingness to pay, simply because he/she can afford it.
}

them, the more readily they give personal information away.

The aim of this article is to show that, by rewarding consumers for the disclosure of information, it is possible to design a form of first-degree price discrimination that is mutually advantageous to both firms and consumers. While such a pricing model could be used for many products, this article focuses on the case of digital music and shows how using mutually advantageous price discrimination could be used to mitigate the effects of consumer piracy and, potentially, to increase revenues in the music industry.

This is particularly important at a time when 'traditional' solutions used to curb consumer piracy appear to have had a very limited effect. Digital Rights Management systems, which were at some point deemed as a 'silver bullet' against piracy, have remained highly ineffective, as discussed in Rayna and Striukova (2008a, b), Sinha et al. (2010) and Vernik et al. (2011), and are nowadays seldom used for digital music. Likewise, 'three-strike' laws, which have been adopted in some countries (e.g. France, New Zealand, United Kingdom), have also proven generally ineffective because they do not tackle the question of incentives (Rayna and Barbier 2010).

At the same time, new revenue models, such as 'free with advertisement' (e.g. Spotify, Deezer) or 'pay what you want' (Bandcamp) have emerged and, in some cases, become quite popular. While such models may be, at times, successful (Kim et al. 2009; Gneezy et al. 2010), they often result, overall, in lower revenues for creators and tend to loosen the relationship between social value and actual rewards.

The model presented in this article investigates the conditions under which mutually advantageous first-degree price discrimination is achievable. Besides discussing the optimal amount of the reward, this article also considers potential pitfalls, as consumers could, indeed, attempt to manipulate personal data collected in order to artificially decrease the perceived willingness to pay (thereby making a financial gain). The robustness of the model with regard to such opportunistic behavior is also investigated.

The first section of this article reviews the literature related to price discrimination (first degree one, in particular). The second section introduces the concept of mutually advantageous first-degree price discrimination. The third section presents how such a pricing model would be used in the case of digital music. The fourth section introduces an analytical model that assesses the feasibility of mutually advantageous price discrimination. The fifth section develops the model further by taking opportunistic behavior into account. The final section discusses the limitations of the analytical model as well as practical considerations. 


\section{The economics of digital price discrimination}

Until recently, it has been a widely shared belief that first-degree price discrimination was little more than a theoretical curiosity. It is thus not surprising that, in contrast to second and third-degree price discrimination, which have been abundantly discussed (Schmalensee 1981; Bester and Petrakis 1996; Hamilton and Slutsky 2004; Liu and Serfes 2005; Galera and Zaratiegui 2006; Malueg and Snyder 2006), the literature devoted to first-degree price discrimination is comparatively scarce.

Nonetheless, the advent of the internet (and of the digital economy, in general) has brought first-degree price discrimination back into focus. The first reason for that is that digital technologies make it possible, for the first time, to accurately (if not fully) observe the behavior of consumers, thereby enabling to estimate (or even fully reveal) their valuation of digital goods or services (Ulph and Vulkan 2000; Taylor 2004; Acquisti and Varian 2005). Besides the early 'proof of concept' delivered by Amazon in 2000, which was based on information collected through internet cookies (Villas-Boas 2004), technologies such as Digital Rights Management systems (embedded in music, video files or games) provide firms with abundant information about consumers' consumption patterns (Rayna and Striukova 2008a, b). More recently, the advent of big data, which enables to obtain an even more accurate picture by combining the data collected from a particular consumer with a large quantity of data of similar customers (e.g. Apple's "Genius" functionality in iTunes), has brought companies even closer to a perfect valuation of willingness to pay. Hence, first-degree price discrimination is, more than ever, closer to becoming a reality.

This has led to a renewed interest of academics, who have started to investigate the consequences of first-degree price discrimination in imperfectly competitive environments. Hazledine (2006), for example, extends the standard Cournot-Nash oligopoly model with first-degree price discrimination. Encaoua and Hollander (2007) analyze quality decisions in a vertically differentiated duopoly where first-degree price discrimination is made possible. Further research has also permitted to widen the scope of firstdegree price discrimination by relaxing some assumptions. Gans and King (2007), for example, demonstrate that the usual assumption that monopolists need to prevent resale in order to first-degree price discriminate is, in fact, not required, even in the case when costless arbitrage markets exist. Finally, Villas-Boas (1999) has investigated the role of purchase history on individualized pricing in a duopoly.

Meanwhile, an important stream of literature has been discussing price discrimination from the standpoint of versioning (Shapiro and Varian 1999; Ulph and Vulkan 2000;
Acquisti and Varian 2005; Bandulet and Morasch 2005) or customizing (Bandulet and Morasch 2005). However, although versioning and customization may lead to a market outcome similar to first-degree price discrimination, it is not, per se, first-degree price discrimination. Indeed, they necessarily imply different products (versions) sold, which leads, at best, to an extreme case of market segmentation, where each consumer has become a market segment. This makes versioning closer to second-degree price discrimination (where consumers self-select the 'formula' best-suited for them). The present article, in contrast, focuses on the ability firms may have to charge different prices for the exact same good or service within the same time frame.

Besides the fact that recent technological progress has made first-degree price discrimination feasible, the other reason to bring this form of price discrimination into focus seems, so far, to have been overlooked. Indeed, the emergence of the digital economy has not only made first-degree price discrimination achievable, but also made socially desirable. The main economic issue associated with digital goods is that they behave as public goods ${ }^{5}$ and result in market failure. In the case of public goods, economic efficiency requires such goods to be priced at a rate equal to the willingness to pay of each consumer (Lindahl 1958; Foley 1970). Because this is exactly what happens with first-degree price discrimination, this form of pricing would enable an efficient market outcome.

Furthermore, first-degree price discrimination has implications in terms of welfare distribution that make it particularly relevant for digital goods. Indeed, such goods are characterized by a high (usually sunk) initial fixed production cost and a low (often negligible) reproduction cost. Consequently, in a perfectly competitive environment, the market price for such goods would be close to zero, hereby preventing producers to recover their initial investment (Arrow 1962).

The traditional solution to this problem has been to create 'intellectual monopolies' (through Intellectual Property Rights) to artificially raise the market price. However, price increase leads to a decrease in social welfare (since consumers willing to pay at least the marginal cost of production may be prevented from consuming the good because of the higher monopoly price), so there is a tradeoff between under-provision and under-utilization (Arrow 1962). In contrast, first-degree price discrimination enables both an optimal output (and the same total surplus as perfect competition) and sufficient incentives for producers, as the higher revenues enable to recover the initial production costs.

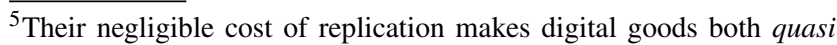
non-rival and non-excludable and, hence, public goods (Rayna 2008).
} 
Hence, first-degree price discrimination has properties that make it particularly suitable in the case of digital goods. However, this can only happen if consumers are willing to accept it, which, considering the uproar that followed Amazon's attempt to first-degree price discriminate, is unlikely to happen. Anticipating the financial loss resulting from first-degree price discrimination, consumers with a higher willingness to pay are unlikely to reveal personal data, or might even attempt to manipulate the information they reveal, thereby preventing first-degree price discrimination. For instance, Taylor (2004) shows that consumers with a high willingness to pay might even engage in strategic demand reduction when confronted with high prices, if they anticipate that personal information is used to price-discriminate them.

It is, thus, not surprising that versioning has become the most popular form of price discrimination online, since the personalization of products/services it entails provides consumers with reasons to accept revealing information (Acquisti and Varian 2005). Unfortunately, as noted in Shapiro and Varian (1999), versioning often requires the creation of "value-subtracted" versions, which is socially inefficient.

Enabling first-degree price discrimination hence requires finding a model where both consumers and producers find it acceptable to adopt this form of pricing. The following section discusses how this can be achieved by rewarding consumers for their disclosure of personal data.

\section{The mutually advantageous first-degree price discrimination principle}

Although consumers do value privacy, they are ready to reveal personal information, as long as they are adequately rewarded for this disclosure (Acquisti and Varian 2005; Hann et al. 2002, 2007a, b). It can be thus expected that, if properly rewarded, consumers would be willing to give up enough privacy to enable firms to use first-degree price discrimination. The question is, however, whether mutually advantageous disclosure is feasible, i.e., whether consumers can be sufficiently rewarded to incite them to disclose enough information, while keeping profits of firms sufficiently high, despite the reward.

Using the economic concept of surplus enables to demonstrate that it is, indeed, possible. Figure 1 represents the demand function of a consumer for undifferentiated digital products. ${ }^{6}$ It is assumed that, as for most digital

\footnotetext{
${ }^{6}$ Without changing the results of the model, it can also be seen as the combined demand function of all consumers for a particular digital product.
}

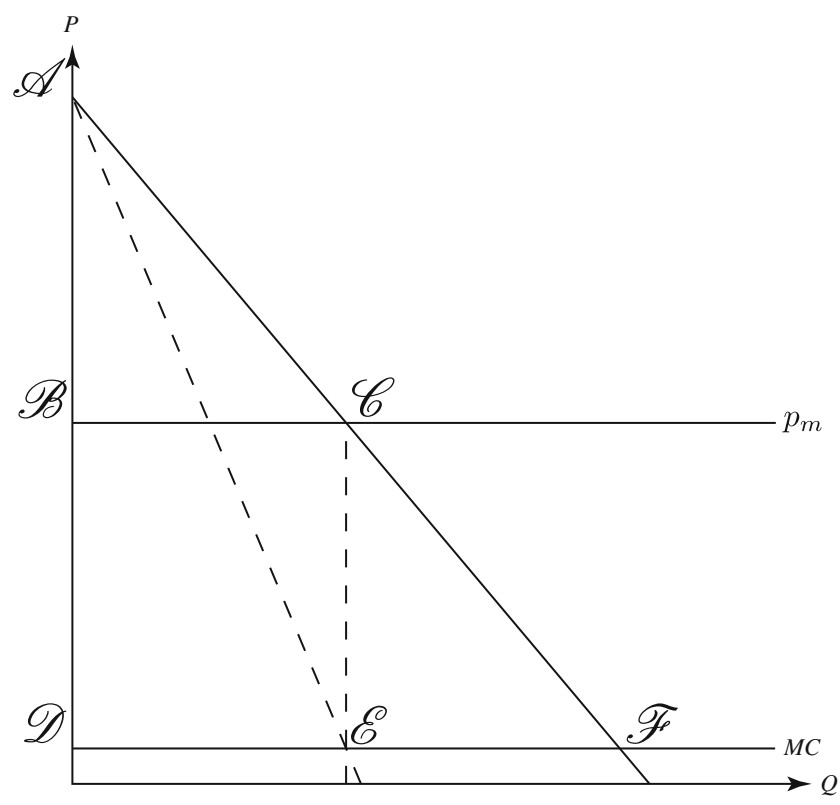

Fig. 1 Demand and surpluses

products, the marginal cost of production is low and constant. Because firms producing digital goods necessarily have some degree of monopoly power (as otherwise the competitive price would be too low to recover the initial investment), the case of a single monopoly is considered.

With uniform pricing, the market price would be $p_{m}$. The producer surplus, which is also the profit, is the area $\mathscr{B} \mathscr{C} \mathscr{E} \mathscr{D}$. The consumer surplus, which measures their welfare, is the area $\mathscr{A} \mathscr{B} \mathscr{C}$.

If the firm was able to collect enough personal data to engage in first-degree price discrimination, it would capture the whole surplus and the producer surplus/profit would become $\mathscr{A} \mathscr{D} \mathscr{F}$, while the consumer surplus would be equal to zero. Yet, it can be assumed that consumers would, nonetheless, be willing to accept price discrimination as long as they obtain at least the same surplus as without price discrimination.

This means that, provided that the firm is willing to pay an amount equal to $\mathscr{A} \mathscr{B} \mathscr{C}$, in exchange for personal data disclosure, consumers would accept to be price discriminated and pay a price equal to their reservation price/willingness to pay. In such a case, the resulting profit/surplus for the firm would be $\mathscr{B} \mathscr{C} \mathscr{F} \mathscr{D}$, which is greater than the profit with uniform pricing $\mathscr{B} \mathscr{C} \mathscr{E} \mathscr{D}$, and the net gain for the firm would be $\mathscr{C} \mathscr{F} \mathscr{E}$. Because consumers would be as well off as before and the firm strictly better off, this form of rewarded first-degree price discrimination would be clearly mutually advantageous. ${ }^{7}$

\footnotetext{
${ }^{7}$ For the sake of argument, it can be assumed that the firm pays a small amount over $\mathscr{A} \mathscr{B} \mathscr{C}$ in order to make consumers strictly better off.
} 
In a perfectly competitive environment, market price would be equal to marginal cost. The consumer surplus would be the area $\mathscr{A} \mathscr{D} \mathscr{F}$ and the producer surplus would be equal to zero. Hence when offering a reward of $\mathscr{A} \mathscr{B} \mathscr{C}$, the firm gains an extra profit equal to the deadweight loss that necessarily arises in a monopolistic situation with uniform pricing. Thus, from a social point of view, this would lead to a Pareto improvement over the monopolistic/oligopolistic situation. ${ }^{8}$ Furthermore, in comparison to perfect competition (for which there is no deadweight loss either), mutually advantageous first-degree price discrimination enables firms to obtain a positive profit, thereby permitting initial investment sunk costs to be recovered. Consequently, first-degree price discrimination with mutually advantageous disclosure is statically equivalent and dynamically superior to perfect competition.

\section{Mutually advantageous first-degree price discrimination in practice: the case of digital music}

In practice, mutually advantageous first-degree price discrimination simply requires that consumers, once price discriminated, never pay more than what they would have paid with uniform pricing. Taking the example of digital music, where a track typically costs $\$ 0.99$, this means that the minimum reward consumers would accept to disclose enough personal information to enable firms to price discriminate is such that they never pay more than $\$ 0.99$ for a track. Hence for any willingness to pay calculated above this price, firms will have to provide a "refund" equal to the difference between the willingness to pay and the uniform price.

While such a pricing model does not, in fact, change anything for all the tracks that consumers value at $\$ 0.99$ or more, it changes everything for tracks for which reservation prices are less than $\$ 0.99$, as it is for these tracks that the mutually advantageous trades take place. Although a rational consumer would never buy something at a price above his/her reservation price, in the case of digital goods, consumers have other alternatives as they can (and often do) download copies of these goods illegally. Indeed, the key issue is that the fact that consumers do not value something for as much as the market price does not mean that they do not value it at all. Likewise, the cost of 'serving' one extra customer in the digital world is negligible and any amount, even very small, collected as a result of a sale would increase the profit of the seller.

\footnotetext{
${ }^{8}$ The principle is similar to Calzolari and Pavan (2006), who show that decrease in privacy can lead to Pareto improvement when none of the concerned parties are harmed by the disclosure.
}

Mutually advantageous first-degree price discrimination hence unlocks a wide range of low value trades that are nonetheless profitable for both sides. Interestingly, the additional mutually advantageous trades that are enabled by this model relate to the right-hand side of the demand function, which corresponds to the less valued - or less 'demanded' goods. Hence, it can be seen as a way to monetize the 'long tail'.

Although this pricing model does not intrinsically prevent piracy, it reduces the attractiveness of illegal downloads, as it enables consumers to purchase tracks (or albums) of lesser value for what they are actually worth to them. ${ }^{9}$ Considering the costs (search costs, learning costs) and risks (viruses, prosecution, fines) of piracy, it is rather unlikely that many consumers will find it worth engaging in it just to save a few cents.

Figure 2 provides a description of how such a system would function in practice. For a particular track (or album) consumers would be offered a choice between "buy" (paying a flat fee, which is the current practice) and "try". In the latter case, it means that they let the company access all the personal data required to calculate their willingness to pay, in exchange for the guarantee that they will never actually pay more than the flat price. If they accept, a monitoring system is installed on all devices used to consume the track, after which the track itself is downloaded. A trial period, during which personal data are collected and analyzed, ensues. The trial period ends when enough data have been collected about consumption of the track itself, as well as other parameters (consumption of other tracks, music in general, etc.), to calculate accurately the willingness to pay for the track. Interestingly, this means that the trial period may be of a different length depending on the consumer, the artist, the genre of the track, etc. As noted in Rayna (2008) such a type of customized trial period is essential to reduce piracy incentives related to 'sampling' (and linked to the fact that music is an experience good).

Once the willingness to pay has been calculated, there are two possible cases. If the willingness to pay is estimated to be lower than $\$ 0.99$, the consumer is offered to buy the song for a price equal to the calculated willingness to pay. If the calculated willingness to pay is above $\$ 0.99$, the consumer is 'refunded' of the difference between the willingness to pay and $\$ 0.99$ (in order to be left as well off as before) and is offered to pay a price of $\$ 0.99$. In both cases, if the consumer agrees, payment takes place and the track is permanently added to the consumer's

\footnotetext{
${ }^{9}$ In that sense, this model takes the opposite approach to traditional Digital Rights Management, which tries to prevent piracy without changing incentives.
} 


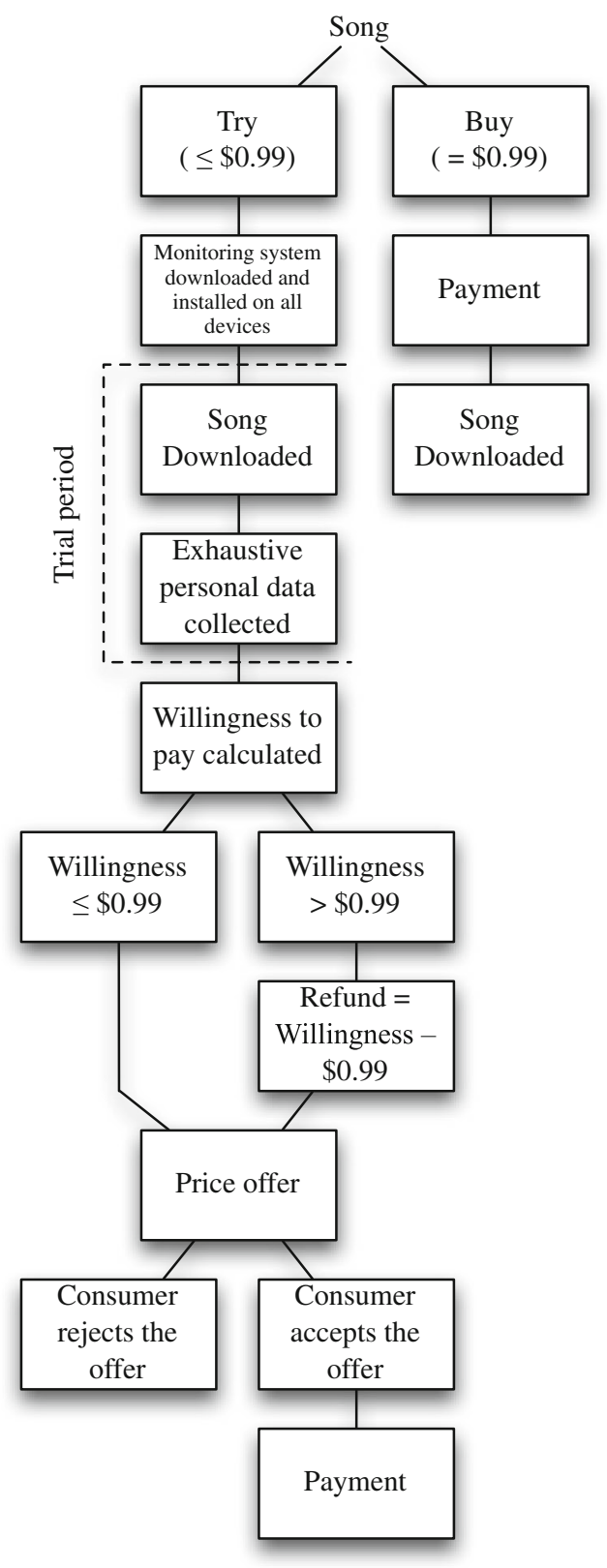

Fig. 2 Sequence of first-degree mutually advantageous price discrimination for digital music

library. The consumer has, in both cases, the possibility to reject the offer and can decide against buying the track.

\section{A model of mutually advantageous first degree price discrimination}

The aim of this section is to present an analytical model that demonstrates the validity of the mutually advantageous price discrimination model.
A monopolist is assumed to be supplying the whole market. It is further assumed that the marginal cost of the product is constant and equal to zero. ${ }^{10}$ In addition:

Assumption 1 (Quasi-linearity) Utility functions of the consumers are quasilinear.

Since quasi-linearity implies that no income effects exist, this ensures that the consumer surplus is an accurate measure of consumer welfare.

Assumption 2 (Full Observability) A monitoring system enabling to fully observe reservation prices/marginal valuations of consumers is available at a constant fixed cost.

Since monitoring requires a one-off fixed cost (presumably sunk), it is left aside in the following analysis. ${ }^{11}$

The market demand function is:

$D(p)=b-a p$

When charging a uniform price, the profit maximizing price, $p_{U}{ }^{*}$, and quantity, $q_{U}{ }^{*}$, for the monopolist are:

$p_{U}^{*}=\frac{b}{2 a}$

$q_{U}^{*}=\frac{b}{2}$

In this case, the consumer $\left(C S_{U}\right)$ and producer surpluses $\left(P S_{U}\right)$ are:

$$
\begin{aligned}
& C S_{U}=\int_{p_{U^{*}}}^{\bar{p}} D(x) d x=\frac{b^{2}}{8 a} \\
& P S_{U}=\int_{0}^{p_{U^{*}}} q_{U^{*}}{ }^{*} d x=\frac{b^{2}}{4 a}
\end{aligned}
$$

Where $\bar{p}$ is such that $D(\bar{p})=0$. As expected in such a monopolistic environment, the total surplus, $T S_{U}$, is inferior to the total surplus that would have been obtained in perfect competition, $T S_{C}$ :

$T S_{U}=C S_{U}+P S_{U}=\frac{3 b^{2}}{8 a}$

$T S_{C}=\int_{0}^{\bar{p}} D(x) d x=\frac{b^{2}}{2 a}$

A deadweight loss exists due to the price distortion introduced by the monopolist:

$D W L_{U}=\int_{0}^{p_{U}^{*}} D(x)-q_{U}{ }^{*} d x=\frac{b^{2}}{8 a}$

\footnotetext{
$\overline{{ }^{10} \text { Identical result can be obtained with a positive and constant marginal }}$ cost by substitution of variables. Results obtained with increasing marginal cost are not qualitatively different from the ones obtained in this model.

${ }^{11}$ This assumption is further discussed in section "Limitations and practical considerations".
} 
The producer is assumed to be unable to observe the behavior of consumers (besides what is purchased and at which price) without their consent. However, the producer can, with the agreement of the consumers, use monitoring systems enabling to fully observe the reservation prices and demand function of each consumer. The producer can subsequently engage in first-degree price discrimination and charge each consumer, for each unit of good, a price equal to his/her reservation price (or marginal valuation).

First-degree price discrimination leads to the producer capturing the whole surplus. If one considers the case of a representative consumer (i.e. a homogenous population of consumers with identical preferences), the switch to firstdegree price discrimination clearly causes a loss of welfare for the consumers. In the case of a continuum of consumers with different reservation prices, consumers with high valuation for the good (i.e. consumers who would purchase the good at the monopoly price) are made worse-off by first-degree price discrimination, while consumers with low valuation can be made better off due to the fact that they are now able to consume the good. ${ }^{12}$ In this case, the situation for the producer is only profitable if both high valuation and low valuation consumers accept to be monitored.

The producer could convince consumers to reveal their valuation by giving them a reward $R$ for their disclosure. In this case, the participation constraints of consumers and producers in first-degree price discrimination with rewarded disclosure are:

$C S_{D}+R \geqslant C S_{U}$

$P S_{D}-R \geqslant P S_{U}$

If these two conditions are met, consumers accept to reveal their valuation (or accept to be monitored, thereby revealing their valuation) and the producer engages in firstdegree price discrimination. When consumers fully disclose their reservation prices, the producer does not have any incentive to depart from perfect first-degree price discrimination. Thus, the consumer surplus is null and the producer captures the full surplus:

$C S_{D}=0$

$P S_{D}=\int_{0}^{\bar{p}} D(x) d x=\frac{b^{2}}{2 a}$

It can be noted that the total surplus with first-degree price discrimination, $T S_{D}$ is higher than the monopolistic total surplus and is, due to the absence of deadweight loss, equal to the total surplus in perfect competition:

$T S_{D}=P S_{D}=T S_{C}$

\footnotetext{
${ }^{12}$ These are standard welfare effects of price discrimination, as detailed in Varian (1985).
}

Definition 1 Mutually advantageous first-degree price discrimination is defined as a situation where a switch from uniform pricing to perfect personalized pricing leads to a Pareto improvement, i.e. the welfare of each party with perfect price discrimination is at least equal to their welfare with uniform pricing and the welfare of at least one party is strictly superior to the welfare obtained with uniform pricing.

Remark Since, by definition, mutually advantageous firstdegree price discrimination requires a Pareto improvement, mutually advantageous first-degree price discrimination cannot take place in a perfectly competitive environment. In a perfectly competitive environment, the total surplus is maximal and no Pareto improvement can take place.

Proposition 1 (Mutually Advantageous First-Degree Price Discrimination with Rewarded Disclosure and Full Observability) When the behavior of consumers can be, with their consent, fully monitored, a mutually advantageous firstdegree price discrimination, as defined in Definition 1, is achievable provided that:

1. The original economic environment is imperfectly competitive.

2. The consumers are paid a reward $R$, for disclosing their reservation prices, such that:

$$
C S_{U} \leqslant R \leqslant C S_{U}+D W L_{U}
$$

Proof Proof given in Appendix.

Corollary 1 Mutually advantageous first-degree price discrimination is Pareto optimal.

Proof The total surplus is maximal and the deadweight loss is null under first-degree price discrimination. Therefore, no further Pareto improvement can be made.

An obvious form of mutually advantageous first-degree price discrimination takes place when the reward paid to the consumers is exactly equal to their original consumer surplus. In fact, if the producer decides on the amount of the reward, it is very likely that a reward equal to the original consumer surplus will be chosen, since it is the smallest compatible reward and it provides the highest possible profit to the producer.

Proposition 2 (Profit Maximizing Reward) The profit maximizing reward, $R^{*}$, is defined as the smallest possible reward acceptable for the consumers:

$R^{*}=C S_{U}=\frac{b^{2}}{8 a}$ 
When reservation prices are fully disclosed and $R^{*}$ is given as a reward, the producer surplus is maximal and the producer obtains all the gains from switching to firstdegree price discrimination. These gains are equal to the monopolistic deadweight loss $D W L_{U}=\frac{b^{2}}{8 a}$.

\section{Proof Omitted}

Thus, this model demonstrates that it is possible to find a reward that is compatible with the participation constraints of both firms and consumers. It is to be noted that although consumers do not actually obtain a net financial gain (since the reward leaves them just as well off as before), other benefits are generally sufficient to trigger the release of personal data (Hui et al. 2006; Hann et al. 2007b; Krasnova et al. 2010). Furthermore, several studies (Spiekermann et al. 2001; Berendt et al. 2005; Acquisti and Gross 2006) have demonstrated that consumers tend to disclose more information, in practice, than what their concerns towards privacy would lead to think.

\section{The importance of not being earnest}

The switch from uniform pricing to first-degree price discrimination is not, a priori, supposed to lead to any change in the behavior of consumers. However, if it is assumed that the original market demand curve is the sum of the individual demands of heterogeneous consumers and that these consumers remain anonymous (e.g. they are not identified according to their valuation) until the switch to personalized pricing is made, there may be an incentive for consumers to alter their behavior once the change has occurred.

Indeed, the amount of the reward given to consumers in exchange for disclosing their valuation is based on their consumer surplus with uniform pricing. Moreover, once first-degree price discrimination is introduced, the surplus of the consumers is, without the reward, equal to zero. Thus, consumers may have an incentive, once the switch to personalized pricing has occurred, to masquerade as a consumer with a lower willingness to pay, by manipulating the personal data they supply.

Figure 3 provides an illustration of what such a behavior would be. The original demand function of a type-1 consumer, before the switch to personalized pricing, is $\mathscr{D}_{1}$. After the switch to first-degree price discrimination, the consumer is charged her marginal valuation for each unit of good situated above the marginal cost (the consumer surplus is, thus, null) and gets a reward equivalent to her consumer surplus with uniform pricing (represented on Fig. 3 by the crosshatched triangle). Nonetheless, if this consumer were to masquerade as a type- 2 consumer, who has a lower

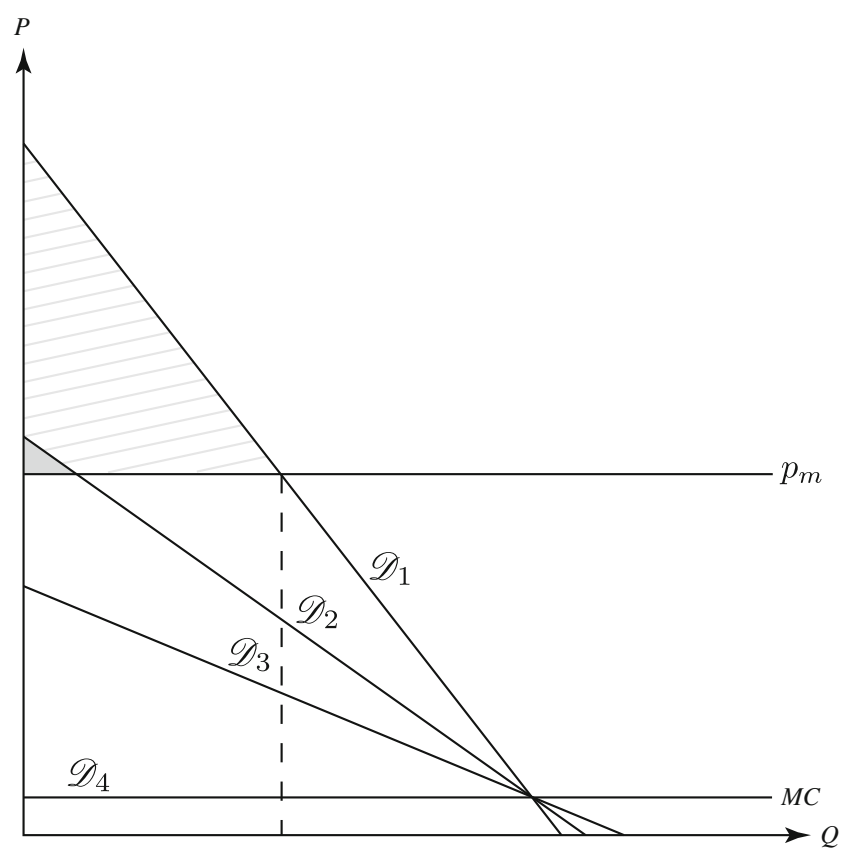

Fig. 3 Consumer masquerading and its effect on reward and surplus

valuation and has a demand function $\mathscr{D}_{2}$, the consumer would pay for each unit of the good the marginal valuation of a type- 2 consumer instead of the marginal valuation of a type- 1 consumer. The consumer would then benefit from a consumer surplus equal to the surface between $\mathscr{D}_{1}$ and $\mathscr{D}_{2}$. This would, of course, come at a cost, since this masquerading consumer would receive the lower reward of a type- 2 consumer (represented on Fig. 3 by the plain grey triangle).

The more the consumer masquerades and the higher her surplus becomes, at the expense of the reward, which becomes smaller. If the consumer masquerades for a type3 consumer, her reward in null, since type- 3 consumers are not consuming the good when there is uniform pricing $\left(\mathscr{D}_{3}\right.$ is located below $p_{M}$ ). Ultimately, consumers could pretend that they are type-4, whose valuation for the good is constant and equal to the marginal cost. In this case, the price they would be asked to pay for each unit of the good would be equal to the marginal cost and they would capture the whole surplus (note that if all consumers adopted this behavior, the situation would be equivalent to the perfectly competitive case).

For consumers to be able to masquerade, one needs to assume that the producer does not have a full monitoring capability. Although the producer may have a perfect monitoring ability (in the sense that it accurately observes the behavior of consumers and, from this observation, correctly calculates the reservation prices), it may not be possible to monitor all the aspects of the life of consumers. For instance, a monopoly supplying music could be able to perfectly monitor the consumption of music taking place by 
means of computers and other high-tech devices, but remain unable to monitor consumption through other, less technologically advanced, means, such as audiotapes, CDs, radio, etc. Consumers would then be able to alter the perception the producer has of their consumption (and thus of the marginal value) by substituting consumption with monitored devices for consumption with unmonitored devices.

Assumption 3 (Personal data manipulation) It is assumed that consumers have the possibility to manipulate the personal data communicated to the firms, hereby altering the perception the producer has of their demand function. The perceived demand function for consumer $i$ then becomes:

$D_{i}^{\prime}=b_{i}-\left(a_{i}+l_{i}\right) p$

Where $l \in \mathbb{R}^{+}$is the amount of deception ('lie') chosen by the consumer.

Remark When $l=0$, the consumer remains truthful and $\mathscr{D} \equiv \mathscr{D}^{\prime}$. When $l \rightarrow \infty$, the observed demand function becomes flat.

Assumption 4 (Sequentiality) It is assumed that actions of the firm and of consumers are sequential, i.e., the firm decides first whether to engage or not in personalized pricing, and then consumers have the opportunity to remain truthful or to manipulate personal data (Fig. 4).

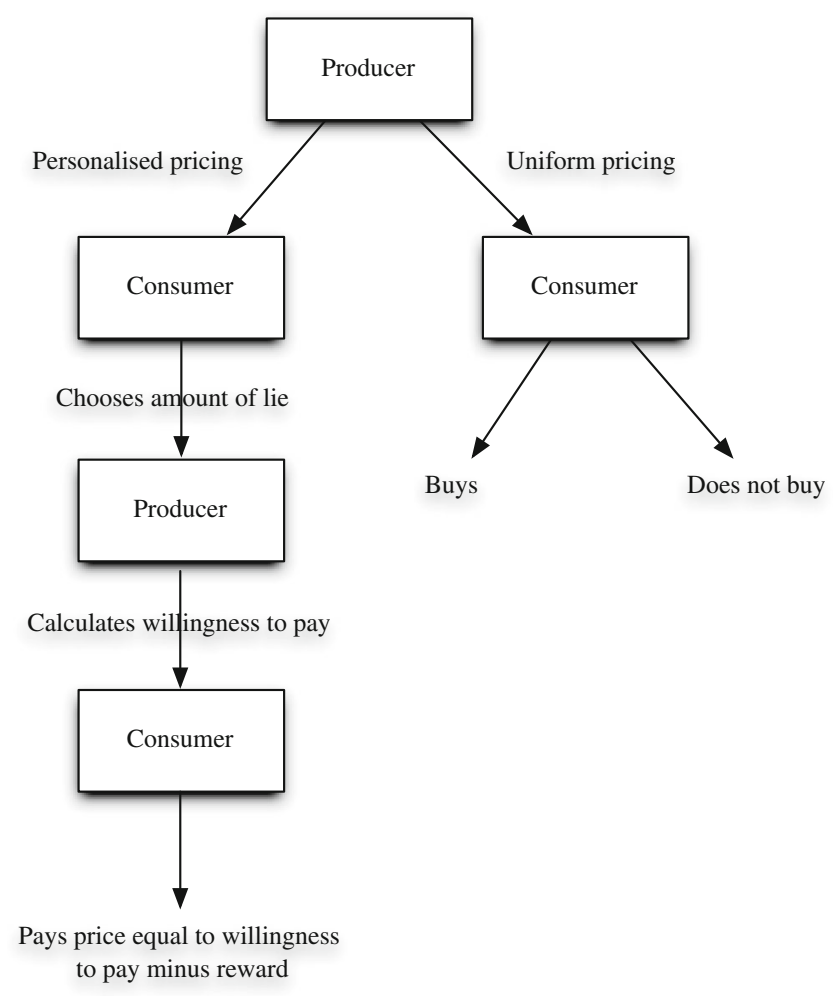

Fig. 4 Sequentiality of decisions of producer and consumers
Assumption 5 (Representative consumer) In the following sections, focus is put on a representative consumer whose behavior will be analyzed:

$D^{\prime}=b-(a+l) p$

Figure 5 shows the inverse demand curves that correspond to both original and masqueraded demand functions.

The first thing that one can notice is that the consumer always obtains a surplus at least equal to the uniform pricing consumer surplus. This is because the decrease in the amount of the reward that occurs when the consumer lies is offset by the gain in consumer surplus. When the consumer lies so much that no reward is given, the consumer surplus obtained is strictly superior to the uniform pricing consumer surplus. Ultimately, when the consumer lies infinitely, she is able to capture the whole surplus.

However, the producer is unlikely to accept this and would most certainly prefer the outcome obtained with uniform pricing. Since, the more the consumer lies, the lower the profit of the producer is, there is an amount of lie that is such that when it is exceeded, the producer does not find it worthwhile engaging in first-degree price discrimination and no Pareto improvement can take place. To this respect, Conitzer et al. (2012) find a similar result in their model when consumers can 'anonymize' for free, which may also prevent Pareto improvements.

Proposition 3 (Mutually Advantageous First-Degree Price Discrimination with Rewarded Disclosure and Partial Observability) When the behavior of consumers can be,

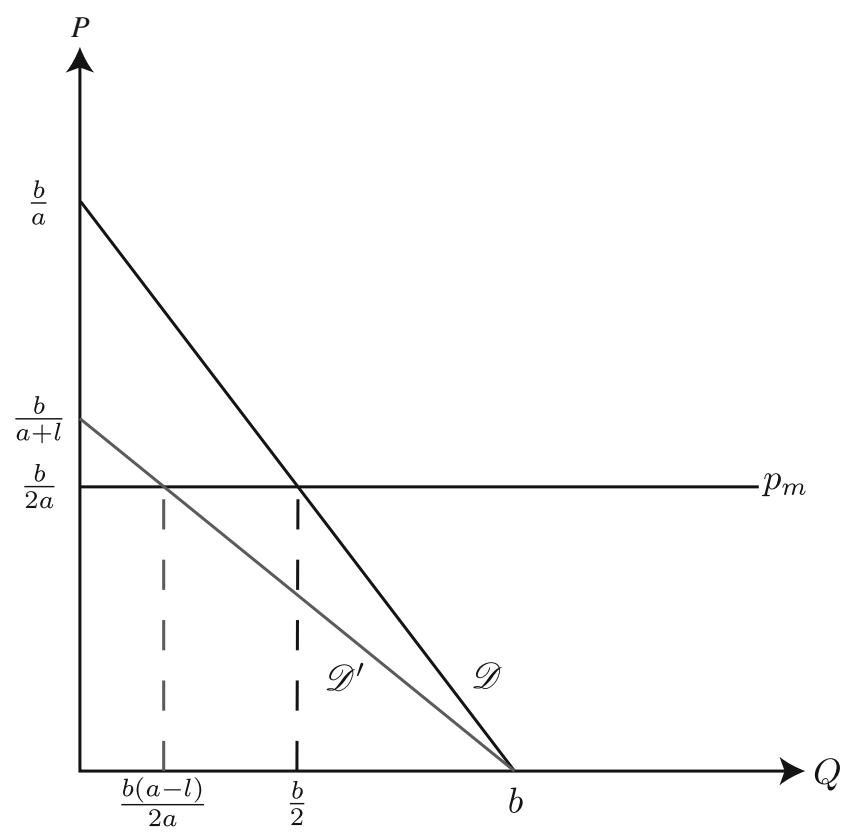

Fig. 5 Actual and masqueraded inverse demand functions of a representative consumer 
with their consent, partially monitored, a mutually advantageous first-degree price discrimination, as defined in Definition 1, is only achievable provided that:

1. The original economic environment is imperfectly competitive.

2. The consumers are paid a reward $R$ for disclosing their reservation prices such that:

$R=C S_{U}$

3. The level of lie chosen by the consumers is such that:

$l \leqslant a$

Proof Proof given in Appendix.

Remark If the reward is higher than the minimal acceptable reward for the consumers, i.e. $C S_{U}<R \leqslant C S_{U}+D W L_{U}$, the maximal level of lie acceptable for the producer is smaller than what is stated in the condition 3 above. If $R=C S_{U}+D W L_{U}$, the acceptable level of lie is $l=0$.

\section{Lying is not costly}

Thus, when consumers can only be partially monitored, the achievability of mutually advantageous first-degree price discrimination depends solely on the truthfulness of consumers. When lying does not entail any cost, consumer obviously choose the maximum amount of lie and thus captures the whole surplus, leaving the producer with a profit equal to zero. Therefore, when consumers can only be partially monitored and lying is costless, mutually advantageous first-degree price discrimination is unachievable.

Proposition 4 (Mutually Advantageous First-Degree Price Discrimination with Partial Observability and no Lying Cost) When the behavior of consumers can only be partially monitored and when consumer can alter their behavior at no cost to masquerade as low valuation consumers, mutually advantageous first-degree price discrimination is never achievable.

Proof Proof given in Appendix.

It is important to note that this situation is, in fact, a moral hazard problem. In the original situation with uniform pricing, consumers do not have incentive to lie. However, as soon as the switch to personalized pricing is made (which corresponds, in fact, to the establishment of a new contract), they have strong incentives to do so. Personalized pricing would lead to a net welfare improvement over the uniform pricing situation. If the actions of consumers were fully observable, the incentives to lie would disappear and a Pareto outcome could be achieved. This is, therefore, a problem of hidden actions, which makes the outcome sub-optimal.

\section{Linear cost of lying}

It is quite likely, though, that lying comes at a cost. Consumers could fool the producer by consuming music on unmonitored devices, such as low-tech audiotapes or CDs, instead of monitored high-tech devices, such as computers, smartphones, tablets or iPod-type media players. However, this would certainly come at the expense of efforts and inconvenience (consumers may have to carry several devices with them). It may also carry additional costs if the consumer has to purchase additional devices. In any case, it is reasonable to assume that lying is increasingly costly, since lying more requires to modify one's consumption behavior to a larger extent. For instance, consumers willing to masquerade as low valuation consumers would have to consume proportionally more goods they value less on a monitored device, while, at the same time, consuming proportionally more goods they value more through alternative means.

Let us first assume that the cost of lying increases linearly:

\section{Assumption 6 (Linear cost of lying)}

$c(l)=k l, k \geqslant 0$

One can expect that the chosen amount of lie $l$ will be the one that equates the marginal gain of lying with the marginal cost of doing so, $k$. Also, logically, there is an amount of the marginal cost $k$ that is such that consumers never find it worthwhile lying.

Proposition 5 (Mutually Advantageous First-Degree Price Discrimination with Partial Observability and Linear Lying Cost) When the behavior of consumers can only be partially monitored and when consumers can alter their behavior to masquerade as low valuation consumers by modifying, by a factor $l$, the demand function observed by the producer and that the cost of lying is linear and of the form:

$c(l)=k l, k \geqslant 0$

two possible outcomes exist:

- $\quad$ if $k \geqslant k^{*}$, consumers do not lie $(l=0)$ and first-degree price discrimination takes place.

- if $k<k^{*}$, consumers choose a level of lie $l>a$ and first-degree price discrimination does not take place.

With:

$k^{*}=\frac{b^{2}}{8 a^{2}}$ 
Proof Proof given in Appendix.

Figure 6 shows net gain curves for the consumer in the three different cases mentioned above $\left(k<k^{*}, k=k^{*}\right.$, $k>k^{*}$ ).

It is worth noting that the critical marginal cost, $k^{*}$, depends positively on the degree of valuation of the consumers $\frac{b}{a}$ :

$\frac{\partial k^{*}}{\partial \frac{b}{a}}=\frac{b}{4 a}>0$

Thus, consumers with a higher valuation for the good are more likely to find it worthwhile lying. Assuming that the marginal cost of lying is the same for all consumers, in a population of heterogeneous consumers, consumers with a high valuation for the good may be inclined to lie while consumers with a lower valuation might decide to remain truthful. Likewise, consumers with a higher valuation are expected to find it worthwhile to lie more $\left(\frac{\partial l^{*}}{\partial b / a}>0\right)$.

\section{Non-linear cost of lying}

It is, in fact, quite sensible to assume that the cost of lying is not linear, but instead that the marginal cost of lying is increasing. Although it should not be too difficult to change the demand curve perceived by the producer by using once in a while an (unmonitored) audio-CD player instead of a computer or a media player, doing so intensively is likely to be grueling, especially at a time when most high-tech devices (if not all devices) are likely to be monitored.

Assumption 7 (Non-linear cost of lying) It is now assumed that the cost of lying is:

$c(l)=l^{k}, k \geqslant 1$

Proposition 6 (Mutually Advantageous First-Degree Price Discrimination with Partial Observability and Non-Linear Lying Cost) When the behavior of consumers can only be partially monitored and when consumer can alter their behavior to masquerade as low valuation consumers by modifying, by a factor $l$, the demand function observed by the producer and that the cost of lying is non-linear and of the form:

Fig. 6 Net gain of the consumer as a function of the level of lie (linear case)

$c(l)=l^{k}, k \geqslant 1$

Mutually advantageous first-degree price discrimination only exists if:

$\frac{a^{k+1}}{b^{2}} \geqslant \frac{1}{8 k}$

In this case, the optimal amount of lie for the consumer is (Fig 7):

$l^{*}=\left(\frac{b^{2}}{8 a^{2} k}\right)^{\frac{1}{k-1}}$

Proof Proof given in Appendix.

In terms of welfare, it is important to note that, due to the cost of lying, the total welfare is inferior to first-degree price discrimination but superior to the uniform pricing case:

$T S_{U} \leqslant T S_{D}\left(l^{*}\right) \leqslant T S_{D}$

And:

$T S_{D}\left(l^{*}\right) \rightarrow T S_{D} \Leftrightarrow l^{*} \rightarrow 0$

$T S_{D}\left(l^{*}\right) \rightarrow T S_{U} \Leftrightarrow l^{*} \rightarrow a$

More lies means a higher surplus for the consumers but this comes at the expense of a lower total surplus. In contrast, fewer lies leads to a higher total surplus but also to a lower consumer surplus.

\section{Limitations and practical considerations}

The model presented in this article adopts the assumptions and methodology of mainstream economics models and, as such, suffers the same limitations. In particular, it is assumed that both consumers and firms are substantively rational and have a perfect access to information about their environment, but also about themselves. Of course, this form of modeling and its implied assumptions, although still widely used, has been criticized in the literature on numerous occasions for being too unrealistic. In particular, the works of Simon (1959) and Kahneman and Tversky (1979) have emphasized the weaknesses of the concept of rationality in standard economic models.

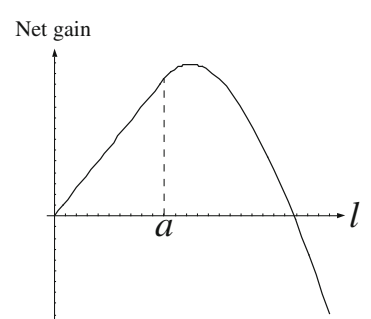

$k<k^{*}$

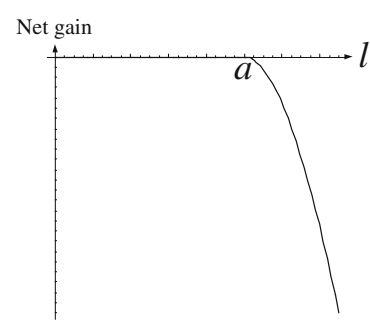

$k=k^{*}$

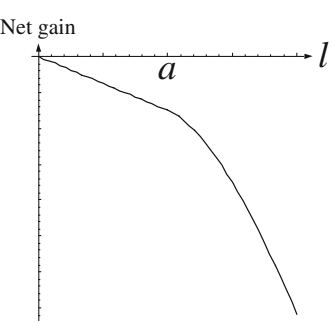

$k>k^{*}$ 
Fig. 7 Net gain of the consumer as a function of the level of lie (non-linear case)
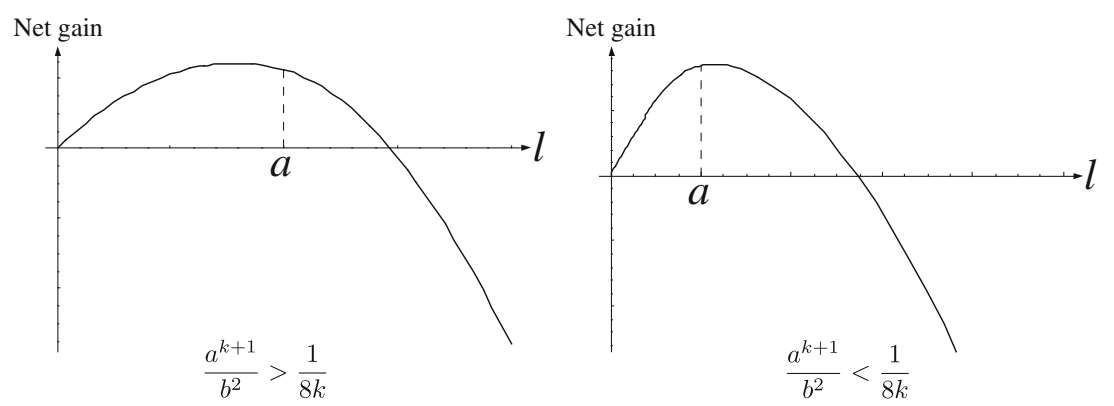

In the case of this article, however, adopting more realistic behavioral assumptions tends to reinforce further the worthiness of the pricing model proposed. Indeed, if one considers, as in Simon (1959), that individuals have a bounded rationality, which entails a limited knowledge of their environment but also of themselves, and limited processing capabilities, the pricing mechanism presented in this article could have a further value, as it can act as a Decision Support System.

Aggregating and analyzing a vast amount of data from many consumers would probably lead the system to know each consumer better than they know themselves. It could know, for instance, that for a particular consumer, a particular 'summer hit' is not just a fad, but will be consumed all her life or, in contrast, that a consumer keeps purchasing albums from one particular artist that she, in fact, never or rarely listens to. Furthermore, in light of the massive amount of digital content available to consumers (there are over 30 million songs on the iTunes Store), such a system would be able to accurately recommend new artists or even new genres, which would make it a very valuable service for consumers. This kind of added value services correspond well, in fact, to the "enhanced personalized services" discussed in Acquisti and Varian (2005) and would, therefore, provide intrinsic motivations to disclose information.

Furthermore, the 'refund' mechanism introduced in the model would enable to artificially create value for consumers. Indeed, consumers generally tend to perceive gains and loses in an asymmetric manner (Kahneman and Tversky 1979), which means that a more expensive offer (e.g. \$120) with a partial refund (e.g. \$20) is generally perceived as having a higher value than an identical offer at the same total price (e.g. \$100). Hence, consumers would perceive more value if they are charged $\$ 3$ for a track (their willingness to pay) and 'refunded' $\$ 2.01$, than if the same track was sold to them for $\$ 0.99$.

Tversky and Kahneman (1981) also demonstrate the existence of a "framing effect", which radically influences people's decision depending on the perception of the context. ${ }^{13}$

\footnotetext{
${ }^{13}$ In Tversky and Kahneman (1981), this is evidenced by changing the wording of the questions, without altering their actual meaning.
}

The question of framing, in relation to privacy and information disclosure, was discussed in Hui et al. (2007) and shows that, indeed, beyond the monetary rewards offered, the manner in which the pricing system is presented to consumers will be of critical importance.

Finally, with regard to rationality, economists generally assume that individuals are only motivated by profit and not by fairness. Yet, one of the reasons why Amazon price discrimination strategy backfired is because consumers identified as having a high willingness to pay found it unfair to have paid more than other consumers for the exact same product. Obviously, one could expect the same issue to arise with the pricing scheme presented in this article. However, it is important to note that, unlike in the Amazon case (or first-degree price discrimination in general), this model has a 'maximum amount of unfairness': $\$ 0.99$.

Indeed, regardless of how high their willingness to pay is, 'high spending' consumers never pay more than $\$ 0.99$ per track (conversely, consumers with the lowest willingness to pay never pay less than $\$ 0$ ). Furthermore, when comparing two consumers, because they have different tastes, it is very unlikely that one will systematically pay more than the other. There will also be many cases when they actually pay the same price $(\$ 0.99)$.

There are countless examples that show that consumers are not always against paying more than others, as long as other consumers can know that they have done so, as spending more may give a greater sense of self-worthiness. Although this is particularly visible with 'brands' and fashion, this could also be the case with this form of pricing. Indeed, it would not be too far-fetched to imagine consumers sharing online their willingness to pay for a particular track or album and competing with one another to become the 'biggest fan' of a particular act.

Another aspect of the model that could be considered as unrealistic is the fact that monitoring costs have been left aside. The reason for that is that monitoring costs are expected to be mainly fixed costs. Indeed, the most significant cost would be the development cost of the monitoring software and of the data mining processes. Once these are properly set-up, what remains are (negligible) maintenance costs. Another type of costs relates to the cost of storage 
and processing user data. These were considered as fixed or negligible in the model for two reasons. Firstly, because if data storage and processing are carried out by the firm, although the quantity of monitoring data and the computing power needed to process them would increase over time, the trend over the past 40 years has been constantly decreasing storage and computing costs (to the point that many cloud services, even from smaller firms, are nowadays offered free of charge). Secondly, firms could decide to adopt a distributed computing approach and keep the data stored on users' devices (with some level of redundancy). Likewise, consumers' computers and devices could supply the computing resources needed to process the data.

Of course, in either case, the initial investment may still be too large for certain firms, especially smaller ones, to engage in mutually advantageous first-degree price discrimination. However, smaller firms would probably not have enough data to accurately estimate willingness to pay. The strength of Apple's iTunes Genius or Google's Instant Mix (and their accuracy in predicting what people want to listen to) precisely lies in the vast amount of user data they are able to gather. ${ }^{14}$ Hence, the pricing mechanism described in this article would be more likely to be carried out by firms of a significantly large size.

There are also practical issues that need to be considered. An important one is the compliance of such a system with existing laws and regulations. For instance, regulatory frameworks, such as the EU 'Directive on privacy and electronic communications' (2002/58/EC), restrict the amount and type of information that can be collected by firms about consumers. As noted in Goldfarb and Tucker (2011), the advent of such regulations has had a significantly negative impact on the effectiveness of online advertising. Similarly, one of the main obstacles of the pricing model presented in this article may well be privacy laws. However, it is to be noted that such laws have been passed because a large part of the population were concerned that data collected were used against them. Since the first-degree price discrimination introduced in this article is actually beneficial to the consumers, it is not unreasonable to think that laws could be amended accordingly.

A second practical issue, with legal implications, relates to the use of data against customers. Indeed, although the maximum price is capped and consumers have the possibility to refuse the quoted price, thereby preventing the company to misuse data to capture more surplus, nothing prevents the firm from using (or selling) the collected data for other products and services than music. Indeed, it is quite possible that the data collected as a part of this music pricing scheme could be used to price-discriminate consumers in other markets. Of course, if that were the case and consumers would become aware of it (or simply if they expect this to happen), this would make mutually advantageous price discrimination unachievable.

A final practical issue relates to users without data. Indeed, while consumers who have been using iTunes (or a similar software) for a while already have data that can be used to determine their willingness to pay (iTunes records which tracks have been played and when, when tracks were added to the library, etc.), calculating the willingness to pay for consumers with no data history is a challenge. Of course, the trial period could be extended until sufficient data has been collected, but this would practically turn the service into a (temporary) free-of-charge 'all-you-can-eat buffet' for such users, since they would be able to try any number of tracks for a significant period of time, before enough information has been collected about their consumption behavior. Furthermore, the data collected might not lead to sufficiently accurate estimates of the willingness to pay, since observed consumption would be taking place in an environment devoid of financial constraints. At this stage, it is not quite clear whether this issue will actually be a significant one and it may well be the case that the information collected on other consumers enables to rapidly 'profile' a consumer without data. If this is not the case, an option could be to require consumers without any data to use flat pricing until there is enough data for them to join the scheme.

A final question is which other goods this model could be applied to. A key aspect of this model is the possibility consumers have to finally decide not to purchase the track/album at the price quoted after the observation period. For this reason, this model may only be applicable to goods that are consumed repeatedly. Indeed, for movies or books, which are typically consumed once only, consumers would have no incentive to accept the quoted price, since they have already consumed the good during the observation period and have no willingness to consume it again. Hence, besides music, this model could be applied to software, games and, possibly, TV Shows. ${ }^{15}$ In any case, as noted in section "Lying is not costly", mutually advantageous first-degree price discrimination is only ever possible when consumption can be significantly monitored, which most likely precludes the use of this model for any non-digital good.

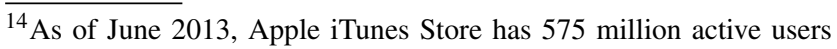
(http://tech.fortune.cnn.com/2013/06/15/apple-algebra-itunes-asymco/).
}

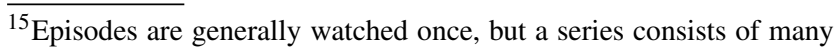
episodes.
} 


\section{Conclusion}

Digital technologies have created both a large potential for economic growth and potentially more sources of market failures. In particular, recent events in ICT (especially in regard to piracy and privacy) have shown the inadequacy of current pricing models.

This article has introduced a new way of resolving conflicting interests while improving social welfare, through mutually advantageous first-degree price discrimination based on personal information. What is particularly important, is that this result is obtained under the assumption that all parties involved behave strategically. Even when firms and consumers behave selfishly, a 'greater good' can be achieved through first-degree price discrimination, because of the additional surplus (which is then shared amongst participants) this form of pricing generates.

However, the feasibility of such a scheme strongly depends on the ability of firms to actually fully monitor the actions of consumers. If their actions remain even partially hidden, a masquerading opportunistic behavior on the consumer side may prevent the establishment of this mutually advantageous way of price discriminating.

An avenue for further research could be to extend the current model, for instance, by considering 'generic' lying cost functions or by considering the feasibility of mutually advantageous price discrimination when consumers are heterogenous. Also, it would be interesting to assess the feasibility and performance of such pricing model within an oligopolistic environment.

Furthermore, it would be interesting to consider mechanisms enabling to impede opportunistic behavior, such as rewarding consumers based on the amount of time they are monitored, and their influence on the feasibility of mutually advantageous first-degree price discrimination. It could also be worthwhile considering what happens if consumers 'dislike' being monitored. While the consequences are fairly obvious when this corresponds to a perceived one-off cost for consumers, this might get far more complex when consumer perceive a cost of giving up privacy that depends on the amount of data revealed.

Acknowledgments This research has been supported by a research grant of the RCUK (Research Councils United Kingdom) Digital Economy Programme. The authors would like to thank Alessandro Acquisti and two anonymous reviewers for their very constructive and helpful comments, which have enabled to significantly improve and clarify the paper.

\section{Appendix}

Proof of Proposition 1 Proof of 1.: if the original environment is perfectly competitive, there is no deadweight loss and $R=C S_{U}$. Consequently, no Pareto improvement can be made. Proof of 2.: The participation constraints Eqs. 9 and 10 can be combined:

$C S_{U} \leqslant R \leqslant P S_{D}-P S_{U}$

Since:

$$
\begin{aligned}
P S_{D}-P S_{U} & =\int_{0}^{\bar{p}} D(x) d x-\int_{0}^{p_{U}{ }^{*}} q_{U}^{*} d x \\
& =\int_{p_{U^{*}}}^{\bar{p}} D(x) d x+\int_{0}^{p_{U}{ }^{*}} D(x)-q_{U}^{*} d x \\
& =C S_{U}+D W L_{U}
\end{aligned}
$$

Equation 19 simplifies as:

$C S_{U} \leqslant R \leqslant C S_{U}+D W L_{U}$

Proof of Proposition 3 Two cases need to be considered, depending on whether a reward is given to the consumer $(l \leqslant a)$ or not $(l>a)$. When $l>a$, the producer surplus is:

$P S_{D}=\int_{0}^{\bar{p}^{\prime}} D^{\prime}(x) d x=\frac{b^{2}}{2(a+l)}$

Thus, for $l>a, P S_{D}<P S_{U}$ and the producer never engages in first-degree price discrimination.

When $l<a$,

$P S_{D}=\int_{0}^{p_{U}} D^{\prime}(x) d x=\frac{b^{2}}{8 a^{2}}(3 a-l)$

$P S_{D}>P S_{U}$ and the producer engages in first-degree price discrimination. When $l=a, P S_{D}=P S_{U}$ and the producer is indifferent between uniform and personalized pricing.

Proof of Proposition 4 Since consumers necessarily obtain a surplus (through reward or actual surplus) at least equal to the uniform pricing consumer surplus, the net additional surplus they earn by lying needs to be considered.

When $l \leqslant a$, the additional gain of surplus obtained by the consumer when lying is:

$\Delta C S_{l \leqslant a}=\int_{0}^{p_{U}^{*}}\left(D(x)-D^{\prime}(x)\right) d x=\frac{b^{2}}{8 a^{2}} l$

When $l>a$, no reward is given to the consumer and the gain obtained (in addition to the original consumer surplus) when lying is:

$\Delta C S_{l>a}=\int_{0}^{p_{U^{*}}} D(x) d x-\int_{0}^{\bar{p}^{\prime}} D^{\prime}(x) d x=\frac{b^{2}}{8 a} \frac{3 l-a}{a+l}$ 
The derivatives of the gain, with respect to the amount of lie, $l$, are:

$$
\begin{aligned}
\frac{\partial}{\partial l} \Delta C S_{l \leqslant a} & =\frac{b^{2}}{8 a^{2}} \\
\frac{\partial}{\partial l} \Delta C S_{l>a} & =\frac{b^{2}}{2(a+l)^{2}}
\end{aligned}
$$

Since the two derivatives are positive (for $a>0$ and $b>0$ ), the consumer would choose, as long as lying is not costly, an infinite amount of lie $(l \rightarrow \infty)$. In this case, the gain of surplus is equal to the monopolistic deadweight loss:

$\lim _{l \rightarrow \infty} \Delta C S_{l>a}=\frac{3 b^{2}}{8 a}=D W L_{U}$

Proof of Proposition 5 The consumer chooses the amount of lie, $l$, for which the marginal gain is equal to the marginal cost. When $l \leqslant a$, the net gain, $\Delta C S_{l \leqslant a}-c(l)$, changes linearly with $l$ :

$$
\Delta C S_{l \leqslant a}-c(l)=\left(\frac{b^{2}}{8 a^{2}}-k\right) l
$$

The net gain is null when the marginal cost, $k$, reaches a critical value $k^{*}$ :

$k^{*}=\frac{b^{2}}{8 a^{2}}$

- When $k>k^{*}, \Delta C S_{l \leqslant a}-c(l)<0$ and $l=0$

- When $k=k^{*}, \Delta C S_{l \leqslant a}-c(l)=0 \forall l \in[0, a]$ and $l \in$ $[0,1]$, in which case, consumers might as well decide, in exchange for an extra reward $\epsilon \rightarrow 0$, to choose $l=0$

- When $k<k^{*}, \Delta C S_{l \leqslant a}-c(l)>0 \forall l \in[0, a]$ and $l=1$

Remark Although it is known, from Proposition 3, that the producer does not engage in first-degree price discrimination when $l>a$, it is still worthwhile studying whether the consumer would indeed have interest to choose such level of lie. When $l>a$, the net gain is:

$\Delta C S_{l>a}-c(l)=\frac{b^{2}}{8 a} \frac{3 l-a}{a+l}-k l$

And:

$\frac{\partial}{\partial l} \Delta C S_{l>a}-c(l)=0 \Leftrightarrow l=\frac{b}{\sqrt{2 k}}-a$

Thus, when $k<k^{*}$, the level of lie $l^{*}$ that maximizes the additional gain for the consumer is:

$l^{*}=\frac{b}{\sqrt{2 k}}-a$

It can be easily checked that $l^{*}>a$ if and only if $k<k^{*}$.
Proof of Proposition 6 Two cases have again to be considered, depending on whether a reward is paid to the consumer $(l \leqslant a)$ or not $(l>a)$. When $l \leqslant a$, the net gain of the consumer is:

$\Delta C S_{l \leqslant a}-c(l)=\frac{b^{2}}{8 a^{2}} l-l^{k}$

$\frac{\partial}{\partial l}\left(\Delta C S_{l \leqslant a}-c(l)\right)=\frac{b^{2}}{8 a^{2}}-k l^{k-1}$

$\frac{\partial}{\partial l}\left(\Delta C S_{l \leqslant a}-c(l)\right)=0 \Leftrightarrow l=\left(\frac{b^{2}}{8 a^{2} k}\right)^{\frac{1}{k-1}}$

The optimal level of lie for the consumer is thus:

$l^{*}=\left(\frac{b^{2}}{8 a^{2} k}\right)^{\frac{1}{k-1}}$

First-degree price discrimination only occurs if $l^{*} \leqslant a$. This is the case when:

$\frac{a^{k+1}}{b^{2}} \geqslant \frac{1}{8 k}$

As in the linear case, it can be noticed that a higher valuation for the good leads to a higher incentive to lie and, hence, a less likely mutually advantageous first-degree price discrimination.

\section{References}

Acquisti, A., \& Gross, R. (2006). Imagined communities: Awareness, information sharing, and privacy on the facebook. In Danezis, G., Golle, P., (Eds.), Lecture Notes in Computer Science: Vol. 4258. Privacy Enhancing Technologies (pp. 36-58). Berlin, Germany: Springer.

Acquisti, A., \& Varian, H. R. (2005). Conditioning prices on purchase history. Marketing Science, 24(3), 367-381.

Arrow, K. J. (1962). Economic welfare and the allocation of resources for inventions. In Nelson, R. R. (Ed.) The Rate and Direction of Inventive Activity, (pp. 609-625): Princeton University Press.

Bandulet, M., \& Morasch, K. (2005). Would you like to be a prosumer? information revelation, personalization and price discrimination in electronic markets. International Journal of the Economics of Business, 12(2), 251-271.

Berendt, B., Günther, O., Spiekermann, S. (2005). Privacy in ecommerce: stated preferences vs. actual behavior. Communications of the ACM, 48(4), 101-106.

Bester, H., \& Petrakis, E. (1996). Coupons and oligopolistic price discrimination. International Journal of Industrial Organization, 14(2), 227-242.

Calzolari, G., \& Pavan, A. (2006). On the optimality of privacy in sequential contracting. Journal of Economic Theory, 130(1), 168204.

Chellappa, R. K., \& Sin, R. G. (2005). Personalization versus privacy: An empirical examination of the online consumers dilemma. Information Technology and Management, 6(2), 181-202.

Conitzer, V., Taylor, C. R., Wagman, L. (2012). Hide and seek: Costly consumer privacy in a market with repeat purchases. Marketing Science, 31(2), 277-292. 
Encaoua, D., \& Hollander, A. (2007). First-degree discrimination by a duopoly: Pricing and quality choice. The B.E. Journal of Theoretical Economics, 7(1). Article 14.

Foley, D. K. (1970). Lindahl's solution and the core of an economy with public goods. Econometrica, 38(1), 66-72.

Galera, F., \& Zaratiegui, J. M. (2006). Welfare and output in thirddegree price discrimination: a note. International Journal of Industrial Organization, 24(3), 605-611.

Gans, J. S., \& King, S. P. (2007). Perfect price discrimination with costless arbitrage. International Journal of Industrial Organization, 25(3), 431-440.

Gneezy, A., Gneezy, U., Nelson, L. D., Brown, A. (2010). Shared social responsibility: A field experiment in pay-what-you-want pricing and charitable giving. Science, 329(5989), 325-327.

Goldfarb, A., \& Tucker, C. E. (2011). Privacy regulation and online advertising. Management Science, 57(1), 57-71.

Hamilton, J., \& Slutsky, S. (2004). Nonlinear price discrimination with a finite number of consumers and constrained recontracting. International Journal of Industrial Organization, 22(6), 737-757.

Hann, I. -H., Hui, K. -L., Lee, S. -Y.T., Png, I. P. (2007a). Analyzing online information privacy concerns: an information processing theory approach. In System Sciences, 2007. HICSS 2007. 40th Annual Hawaii International Conference on System Sciences, (pp. 210b-210b): IEEE.

Hann, I. -H., Hui, K. -L., Lee, S. -Y. T., Png, I. P. (2007b). Overcoming online information privacy concerns: An information-processing theory approach. Journal of Management Information Systems, 24(2), 13-42.

Hann, I. -H., Hui, K. -L., Lee, S. -Y.T., Png, I. P. (2008). Consumer privacy and marketing avoidance: a static model. Management Science, 54(6), 1094-1103.

Hann, I. -H., Hui, K. -L., Lee, T. S., Png, I. P. (2002). Online information privacy: Measuring the cost-benefit trade-off. In 23rd International Conference on Information Systems, (pp. 1-8).

Hazledine, T. (2006). Price discrimination in cournot-nash oligopoly. Economics Letters, 93(3), 413-420.

Hui, K. -L., Tan, B. C., Goh, C. -Y. (2006). Online information disclosure: motivators and measurements. ACM Transactions on Internet Technology (TOIT), 6(4), 415-441.

Hui, K. -L., Teo, H. H., Lee, S. -Y.T. (2007). The value of privacy assurance: an exploratory field experiment. MIS Quarterly, 31(1), 19-33.

Kahneman, D., \& Tversky, A. (1979). Prospect theory: an analysis of decision under risk. Econometrica: Journal of the Econometric Society, 263-291.

Kim, J. -Y., Natter, M., Spann, M. (2009). Pay what you want: A new participative pricing mechanism. Journal of Marketing, 73(1), 4458.

Krasnova, H., Spiekermann, S., Koroleva, K., Hildebrand, T. (2010). Online social networks: why we disclose. Journal of Information Technology, 25(2), 109-125.

Lindahl, E. (1958). Just taxation - a positive solution. In Musgrave, R. A., \& Peacock, A. T. (Eds.). Classics in the Theory of Public Finance. London: Macmillan.

Liu, Q., \& Serfes, K. (2005). Imperfect price discrimination in a vertical differentiation model. International Journal of Industrial Organization, 23(5-6), 341-354.
Malueg, D. A., \& Snyder, C. M. (2006). Bounding the relative profitability of price discrimination. International Journal of Industrial Organization, 24(5), 995-1011.

Rayna, T. (2008). Understanding the challenges of the digital economy: The nature of digital goods. Communications \& Strategies, $71,13-26$.

Rayna, T., \& Barbier, L. (2010). Fighting consumer piracy with graduated response: an evaluation of the French and British implementations. International Journal of Foresight and Innovation Policy, 6(4), 294-314.

Rayna, T., \& Striukova, L. (2008a). Privacy or piracy, why choose? Two solutions to the issue of digital rights management and protection of personal information. International Journal of Intellectual Property Management, 2(3), 240-252.

Rayna, T., \& Striukova, L. (2008b). White knight or trojan horse? The consequences of digital rights management for consumers, firms and society. Communications \& Strategies, 69, 109-125.

Schmalensee, R. (1981). Output and welfare implications of monopolistic third-degree price discrimination. American Economic Review, 71(1), 242-247.

Shapiro, C., \& Varian, H. R. (1999). Information Rules: a Strategic Guide to the Network Economy. Boston: Harvard Business School Press.

Simon, H. A. (1959). Theories of decision-making in economics and behavioral science. The American Economic Review, 49(3), 253283.

Sinha, R. K., Machado, F. S., Sellman, C. (2010). Don't think twice, it's all right: music piracy and pricing in a DRM-free environment. Journal of Marketing, 74(2), 40-54.

Spann, M., Herrmann, A., Sprott, D. (2010). Pricing in electronic markets and networks. Electronic Markets, 20(2), 83-84.

Spiekermann, S., Grossklags, J., Berendt, B. (2001). E-privacy in 2nd generation e-commerce: privacy preferences versus actual behavior. In Proceedings of the 3rd ACM conference on Electronic Commerce, (pp. 38-47): ACM.

Taylor, C. R. (2004). Consumer privacy and the market for customer information. RAND Journal of Economics, 25(4), 631650.

Tversky, A., \& Kahneman, D. (1981). The framing of decisions and the psychology of choice. Science, 211(4481), 453458.

Ulph, D., \& Vulkan, N. (2000). Electronic commerce and competitive first-degree price discrimination. http://else.econ.ucl.ac.uk/papers/ vulkan.pdf.

Varian, H. R. (1985). Price discrimination and social welfare. American Economic Review, 75(4), 870-875.

Vernik, D. A., Purohit, D., Desai, P. S. (2011). Music downloads and the flip side of digital rights management. Marketing Science, 30(6), 1011-1027.

Villas-Boas, J. M. (1999). Dynamic competition with customer recognition. The RAND Journal of Economics, 30(4), 604-631.

Villas-Boas, J. M. (2004). Price cycles in markets with customer recognition. RAND Journal of Economics, 35(3), 486501.

Xu, Y., Tan, B. C. Y., Hui, K. -L., Tang, W. -K. (2003). Consumer trust and online information privacy. In International Conference on Information Systems, 538-548. 